\title{
Instruções para arrecadação do subsídio literário nas Capitanias do Norte do Estado do Brasil
}

Publicam-se dois documentos originalmente manuscritos produzidos em 1773 e 1774, pertencentes ao acervo do Arquivo Histórico Ultramarino de Lisboa(Portugal). Transcritos com adequação de alguns termos e pontuação para o português moderno no intuito de melhor entendimento para seus leitores. Esses documentos são testemunhos patrimoniais desse momento histórico da educação portuguesa.

$\bigcirc$ primeiro documento é um ofício expedido pela Junta da Fazenda de Pernambuco, dirigido a um eminente Secretário da Corte em Portugal, anunciando os trabalhos daquela Junta para completa obediência na cobrança do novo imposto e remetendo à Corte as Instruções elaboradas. $O$ segundo documento, mais extenso e promissor, são as instruções produzidas pela Junta da Fazenda de Pernambuco para a cobrança do novo imposto. Dividido em capítulos e artigos, próprio da linguagem jurídica da época, as Instruções 240 apresentam diretrizes minuciosas de como deve ser cobrado e quem são os responsáveis pelo imposto que financiou a 'educação da mocidade', no final do século XVIII e nas primeiras décadas do XIX no Brasil.

Doutorando Thiago Alves Dias Universidade de São Paulo

\section{Documento 01}

Ilmo. Ex. Senhor,

Em carta que dirigi a $V$. Exa. datada de $1^{\circ}$ do corrente mês [novembro], dava conta a V. Exa. de ter recebido a Real Carta para o estabelecimento dos Subsídios aplicados a Educação da Mocidade; e dizia a Vossa Excelência que a Junta da Fazenda trabalhava no dito estabelecimento, e que sucessivamente participaria a Vossa Excelência tudo o quanto se oferecesse de novo sobre está importante matéria. 
A dita Junta em que Eu presido, depois de bem informada, fez formar as Instruções, que com esta foram presentes a Vossa Excelência, parecendo- the ser as mais próprias, segunda as circunstâncias e distâncias do País, com as quais estou persuadido haverá uma inteira e perfeita arrecadação, principiando a cobrança no primeiro dia do segundo quartel do presente ano, porque assim foi ordenado aos Ouvidores das Comarcas deste Governo.

Sirva-se Vossa Excelência de participar esta notícia a Sua Majestade, para o dito Senhor determinar o que for mais conforme com as suas Reais Intenções.

Recife, Pernambuco, 30 de março de 1774 Ilmo. Exa. Sr. Martinho de Mello e Castro

Manoel da Cunha

\section{Documento 2}

Instruções que a Junta da Administração e Arrecadação da Fazenda Real de Pernambuco pareceu conveniente distribuir aos Ouvidores das Comarcas para regular a pronta arrecadação do Subsídio Literário na conformidade da Real Carta de data de 17 de outubro de 1773.

\section{Capítulo 1 \\ Pelo que respeita os Ouvidores}

$\S 1$

A Sua Majestade foi presente que para melhor arrecadação dos Rendimentos da coleta, que novamente estabeleceu pela Lei de 10 de novembro de 1772 ser-the indispensavelmente necessário o incumbir a inspeção das sobredita arrecadação da Junta da Sua Fazenda para debaixo das direções estas executarem os Ouvidores das Comarcas todas as providências e instruções que a dita Junta thes dirigir nestes termos os ditos Ouvidores devem ficar de acordo para representarem a esta Junta todas aquelas dificuldades ou duvidas que se moverem tendentes ao mencionado respeito. 


\section{$\S 2$}

A cargo dos ditos Ouvidores fica o estabelecimento dos Livros que devem remeter as Câmaras dos seus Distritos, rubricados e encerrados, sem que levem emulumento algum pelo dito trabalho na conformidade do $\S 6$ da lei acima citada.

\section{$\S 3$}

Os Ouvidores receberão de suas respectivas Câmaras no fim de cada quartel uma certidão extraída dos Livros em que se lançarem os manifestos com as declarações que se hão de expressar no Capítulo a respeito das obrigações das Câmaras, e com as ditas certidões, o dinheiro que se tiver cobrado segundo a importância das mesmas, para depois fazer entrega no cofre geral desta Junta.

\section{Capítulo 2}

\section{O que devem observar as Câmaras}

$\S 1$

Sua Majestade considerando em que nos cargos da República costumam ser empregados aqueles vassalos seus de notória probidade, honra, zelo e prudência, esperando desempenho e prósperos e úteis fins que motivou a Paternal Providência do estabelecimento de Professor e Mestre de Escola menores repartidos por todas as terras do seu Real Domínio, em utilidade dos seus Vassalos. É servido encarregar aos que servirem anualmente nas repetidas Câmaras o seguinte.

\section{$\S 2$}

Estando as Câmaras entregue dos Livros que devem ser remetidos como acima se declara terá muito particular cuidado em que a escrituração dos mesmos seja clara e ordenada em medo do que se conheça com facilidade (quando aos lugares em que há arroubação estabelecidas como lugares Olinda, Recife e Boavista), o número, e peso de cada uma das Rezes que se matarem diária e sucessivamente, a importância do subsídio que the 
corresponde as pessoas por cuja causa se pesaram, o dia, mês e ano em que foi pago o dito subsídio, e para maior clareza debaixo do número $1^{\circ}$ se vê a figura dos livros que devem servir para cada uma das arroubações. Semelhantemente para cada uma das Freguesias dos respectivos termos de cada Câmara serão escriturados os Livros como se mostra na figura $n^{\circ} 2$, a qual é diferente a do $n^{\circ} 1$, para variar o modo da arrecadação da coleta, e com o $n^{\circ} 3$ se vê como devem ser escriturados os Livros pelo que respeita ao Subsidio das águas ardentes que se destilam nesse continente, e vem a ser.

\section{$\S 3$}

Estabeleceu Sua Majestade para subsistência dos Professores Mestres das Escolas menores, o módico subsídio de um real em cada libra de carne que se cortar em cada talho, e o de dez réis em cada canada de água ardente dos que se fabricam neste Continente cujos subsídios se devem perceber como abaixo se expressa.

\section{$\S 4$}

Os dilatados termos de cada Câmara faz com que seja impraticável de receberam diariamente os Escrivães das Câmaras os manifestos das aguas ardentes, como também a arrecadação do que deverem as carnes, nestes termos tendo-se consultado e ouvidos muitas pessoas prudentes, práticas e que tem labutadas nos contratos das carnes desta Capitania assentaram uniformes ser mais útil cobrar o dito novo imposto dos Marchantes ao tempo em que matam as Rezes no talho e estabelecidos pelo consentimento dos contratadores, porque como estes tem faz que assistem as matanças para receberem o couro pelo subsídio que thes compete neste mesmo ato, será fácil perceber-se o dito novo imposto e como os ditos fieis dos contratadores, são pessoas de verdade para que se o não o fossem thes não confiariam a administração de um e mais talhos, procurarão as Câmaras o meio (não tendo outras pessoas de que faça maior confidência) de encarregar os ditos fieis da cobrança do sobredito novo imposto dando-lhes por prêmio ou em remuneração do trabalho $1 \%$ do que entregarem a boca do cofre da Câmara. 


\section{$\S 5$}

A falta de balanças e pesos que há nas freguesias do campo como é notoriamente sabido como também da inferior e péssima qualidade das pessoas que ao dito talho vão matar as Rezes, deu motivo a considerar ser mais útil que nesta freguesia se cobre o subsídio por cabeça, e não por arroubas (como se há de praticar nesta Praça, cidades de Olinda, Paraíba e mais vilas principais onde há arroubações, e ser praticável o manifestarem nas Câmaras na conformidade da Leil, regulando as Rezes a sete arroubas cada uma que vem a importar $\$ 224$ réis a razão de $\$ 32$ réis por arrouba, e o real para cada Libra, esta regulação de sete arrouba se faz em atenção aferirem as Rezes que se matam nos referidos talhos o refugo das boiadas (entrando nestes vacas e garrotes) que vem para as cidades e Praças principais.

\section{Capítulo 3 \\ Pelo que respeita as Águas ardentes}

$\$ 1$

244 É bem certo que as Águas ardentes não são gêneros de coletas nas proporções fabricadas diariamente por destilação das canas de açúcar e dos meios. Nos Engenhos de açúcar, e nos partidos dos mesmos é onde há o maior tráfico das ditas destilações e devendo em observância das ordens de Sua Majestade manifestar cada um dos fabricantes qualquer parte do que se ver antes de a extraídas suas fabricas na Câmara do seu Distrito, resultaria deste manifesto feito na respectiva Câmara, dos prejuízos, o primeiro ao Fabricante, o segundo ao Subsídio Literário; porque os mesmos fabricantes the dariam consumo nos seus Distritos como também nos adjacentes furtivamente, sem arrecadação alguma, e para evitar a fraude premeditada, e também por livrar aos ditos Fabricantes descaminhar duas, dez, vinte e mais léguas. As Câmaras nomearão em cada freguesia do seu Distrito dois homens dos mais prudentes e abonados, para exercerem anualmente os cargos, o primeiro de recebedor do subsídio literário, o segundo de Escrivão do dito Recebedor os quais gozaram dos privilégios que gozam os dos mais Rendas Reais; pois Sua Majestade assim declara na sua real carta do estabelecimento do presente subsídio nesta Capitania. 


\section{$\S 2$}

Porém, se as Câmaras parecer que só um Recebedor com seu escrivão não é bastante para arrecadação do subsídio das águas ardentes, nas freguesias que forem mais dilatadas poderão nomear os mais que julgarem necessários. Igualmente as Câmaras devem munir aos Escrivães dos Recebedores de que demos em que se tomem os manifestos os quais cadernos hão de ser rubricados pelos Juízes, e na falta destes pelos vereadores a quem tocar sem que percebam emolumento algum pelos quais se tomaram as contas nos tempos que abaixo se expressarão. Os ditos durarão um só ano no fim do qual ficaram servindo de documento aos assentos que se fizerem nos livros das mesmas Câmaras, e para livrar de toda a confusão na figura $n^{\circ} 4$ se vê claramente o como devem ser escriturados.

\section{$\S 3$}

Os Recebedores quando algum fabricante for manifestar a porção de água ardente que tiver na respectiva fábrica para consumo lhe fará primeiro prestar os juramentos dos Santos Evangelhos para debaixo do mesmo declarar a verdade, e depois deste fará assento das canadas, quartilhos no caderno que acima se refere, e cobrará no mesmo ato dos manifestantes o subsídio a razão de dez réis por canada.

\section{$\S 4$}

Como os Recebedores destas coletas na forma dita que devem ser nomeados pelas Câmaras, e perante quem os Fabricantes hão de fazer os manifesto não são pessoas[aptas] para diferir os juramento aos manifestantes, e porque atendido a dificuldade de irem os mesmos manifestantes imediatamente as Câmaras fazer o manifesto para obviar um e outro embaraço, deverão as Câmaras nas mesmas provisões que passarem aos ditos Recebedores declara- thes comissão para eles deferirem aos ditos juramentos sanando-se deste modo, toda a falta de solenidade e jurisdição. 


\section{$\S 5$}

Os Recebedores em seus respectivos Distritos faram público que sendo denunciado qualquer fabricante de na sua própria casa vender ou extrair alguma porção de água ardente sem haver dado ao manifesto a pena em que incorre, a qual é a de perdimento do dito gênero, e para facilitar as denúncias, concederam aos denunciantes metade do que se apreender, porque a outra metade fica a benefício da coleta. Adverte-se porém, que feita a apreensão em alguma porção de água ardente deve o Recebedor logo dar parte a Câmara, porque sem ordem desta não darão a metade que toca ao Denunciante nem venderam a outra parte que resta a benefício da dita coleta.

\section{Capítulo 4 \\ Dos tempos em que se devem dar contas}

$\S 1$

Os Recebedores tanto pelo que respeita as carnes como as água ardentes que morarem no recinto de dez léguas das suas respectivas Câmaras darão conta nas mesmas todos os meses e os que morarem em maiores distancias das ditas dez léguas declaram de três em três meses na mesma conformidade, entregando nos cofres das Câmaras os dinheiros que tiverem cobrados, e concluídas as ditas contas se fará no caderno termo de ajustadas pelo Escrivão da respectiva Câmara, e sem perda de tempo extraíra dos livros duas certidões, uma pelo que respeita as águas ardentes, outra as carnes, cujas as certidões as devem levar ao Ouvidor com o dinheiro que tiverem cobrado segundo a importância das mesmas. As ditas certidões hão de ser extraídas na forma que a figura $n^{\circ} 5$ aponta.

\section{$\S 2$}

No fim de cada um ano todos os Livros e cadernos dos manifestos serão remetidos a contadoria desta Junta para na mesma se examinarem, e conferirem com as certidões apontadas para depois de liquidas se extrair o mapa geralque S. Majestade determina suba Sua Real Presença. 


\section{Conclusão}

Ocorrendo nas Câmaras alguma dúvida a proporão sem demora ao seu respectivo Ouvidor o qual não sendo de fácil solução fará com a mesma brevidade presente a esta Junta a dissolve-la. Contadoria aos 26 de março de 1774.

Bernardo Vieira de Vasconcelos

\section{Notação documental}

OFíClO do Governador da Capitania de Pernambuco, Manoel da Cunha Meneses, ao Secretário de Estado da Marinha e Ultramar, Martinho de Melo e Castro, sobre as providências tomadas pela Junta da Fazenda Real da dita Capitania acerca dos subsídios para educação da mocidade.

Recife, 30 de março de 1774.

(Arquivo Histórico Ultramarino, Arquivo Central, Conselho Ultramarino, Pernambuco, cx. 11 16, documento 8.864, com anexos).

Doutorando Thiago Alves Dias Programa de Pós-Graduação em História Econômica Universidade de São Paulo E-mail | thiago.dias@usp.br 